\title{
EFFECT OF TWIST ON COTTON YARNS
}

\author{
By A. A. Mercier and Charles W. Schoffstall
}

\section{ABSTRACT}

Yarns were spun in the bureau's experimental cotton mill from 1-inch and $1 \frac{1}{16}$-inch staples, middling grade cotton, using single and double roving organizations. Seven counts of combed yarns ( $1 \frac{1}{16}$-inch staple) and five counts of carded yarns (1-inch staple) were spun. Different twist factors were used for each yarn.

Measurements were made of strength, diameter, angle of twist, and contraction. Correlations of the results graphically with respect to the twist multiplier are shown and discussed. Suggestions regarding the application of these data to the cotton mill are given.

\section{CONTENTS}

II. Need for definite information

III. Purpose and scope

IV. Manufacturing procedure

V. Testing procedure

1. Conditioning

2. Sampling _... 738

3. Breaking strength _.......... 738

4. Yarn count _... 739

5. Diameter of yarn $\ldots \ldots \ldots$

6. Angle of twist_... 739

VI. Discussion of results_._. 740

1. Breaking strength $\ldots$

2. Diameter and angle of twist _...

3. Contraction

VII. The use of these data in the mill

\section{FACTORS THAT AFFECT THE PROPERTIES OF COTTON MATERIAL}

The physical properties of a cotton yarn are extremely important, both from the standpoint of quality of product and cost of production. The strength, regularity, or evenness, absorptivity with respect to moisture or dye, the feel or handle, the cleanliness, and other properties of the finished product must each be considered in the selection of the raw material and the proper manufacturing procedure in the mill.

The factors governing the selection of raw cotton as it is related to the properties of the final product have been fairly well established. 
The long fibers for the combed yarns used in voiles, lawns, airplane fabrics, etc., the shorter fibers for bagging, blankets, etc.; the selection of the grades according to the type of cloth desired; all these features have been established, at least along approximate lines. No manufacturer would attempt to spin fine yarns on a production basis from low-grade short-stapled cotton, nor would he buy highgrade cotton for such a low-grade fabric as osnaburg.

The quality and cost features are definitely related with the processes and settings of the machines, hence the proper organization of mill procedure is even more important than the selection of the raw cotton. When a mill is being planned for the manufacture of a particular kind of material, such as sheeting, for instance, it is very desirable to know the relation of the twist factors to yarn diameter, strength, angle of twist, etc. The best mill organization from the standpoint of cost in this instance is one which will yield maximum production with minimum idle machinery. The difference of a few turns per inch may necessitate additional spinning frames or other machines which are expensive in both initial cost and operation and occupy valuable space. Having once fixed the operating conditions, the manufacturer can seldom afford to make a change; thus it is of increased importance that the best mill organization be adopted initially.

Some mills are equipped to make any type of material, within certain limits, that is ordered. Here a definite knowledge of the relation of the mill organization to the finished product means the satisfactory completion of the order from the standpoint of both quality and cost of product.

In most cases one property is more important than another, and some sacrifice of the other features may be necessary. This is the case, for instance, in the manufacture of toweling where high moisture absorption and softness of feel must be obtained. Some of the strength is generally sacrificed; but, obviously, some middle ground must be selected, for the towel must be capable of withstanding the rigors of the laundry treatment at frequent intervals. So the highest absorptive quality can not always be attained.

A closer analysis of the situation shows that the absorptiveness and the strength of the yarn each depend largely on one manufacturing factor; namely, the twist. Within limits, the lower the swist the higher is the absorptiveness and the lower the strength.

When the selection of the proper manufacturing organization for the toweling is considered from a cost viewpoint, it is found that the higher the twist the greater the cost of production. Now, if it is known what properties certain twist factors produce, an easy selection might be made of the best mill organization. 


\section{NEED FOR DEFINITE INFORMATION}

The mill managers may fully realize the fact that the twist of the yarn affects the finished product very materially and yet be unable to cope with difficulties arising from this condition. Many mills buying their yarn for weaving or knitting are confronted with this situation. Such terms as "filling twist," "warp twist," and "hosiery twist" are frequently used in the yarn market. (Sometimes the word "yarn" is substituted for "twist.") Agreeing on an exact definition for these terms is not easy.

It is recognized that yarns for hosiery and underwear must be soft and pliable in order to run properly on the knitting machines. The desired properties are gained by using a low number of turns per inch. "Hosiery twist" thus indicates that the yarn has few turns per inch. Many of the defects of cotton hosiery occur because of the lack of definite data or a standard definition for "hosiery twist." For instance, yarn from two different sources, the same yarn count and both "hosiery yarns" according to the marks of the respective yarn mills, may be used on the same knitting machine. Because of the differences in twist practice in different mills there are apt to be dissimilarities in the finished product. If the difference is not apparent in the stitch formation, it will show when the hosiery are dyed. Uneven shades or difficulties in pair matching will frequently occur.

Another example is found in connection with the "filling-twist" yarns and "warp-twist" yarns. Warp yarns are subjected to strain in the loom, and thus, if for no other reason, they must have sufficient twist to make them strong enough to prevent excessive breaking. Filling yarns undergo very little strain in weaving. If a manufacturer wants to make a cloth with as little cost as possible so far as twist is concerned, he uses yarns having the least twist, which, according to practical experience, works satisfactorily on the loom. Generally, yarns bought under designations of "warp twist" and "filling twist" approximate these minimum twists unless a definite twist is specified. This results from the close relation of twist to production cost. Unfortunately the idea of what the minimum should be varies in the different yarn mills, so that the terms which express the degree of twist have only vague meanings.

If definite data regarding the effect of twist on the properties of yarn were established, the relation of the yarn to the finished material and to its intended use would receive more attention and there would follow an improvement in yarn manufacture and trading. A weaving. mill could order yarn with a certain twist factor made from cotton having a certain staple and be reasonably sure that, whatever yarn mill made it, it would fulfill definite requirements. This would not be confusing for the yarn mill, for, no doubt, standardization of terminology would be accomplished in due time and "warp twist," "filling twist," "hosiery twist," etc., would have definite meanings. 


\section{PURPOSE AND SCOPE}

The purpose of this paper is to show how twist affects the breaking strength of yarn, the diameter of yarn, the angle of fibers (angle of twist), and the draft necessary to maintain a constant count while increasing the twist.

The raw cotton used was middling grade of 1 -inch and $1 \frac{1}{16}$-inch staples. The 1 -inch cotton was carded and spun into $10 \mathrm{~s}, 15 \mathrm{~s}, 20 \mathrm{~s}$, $25 \mathrm{~s}$, and $30 \mathrm{~s}$ yarns. The $1 \frac{1}{16}$-inch cotton was combed and spun into $10 \mathrm{~s}, 15 \mathrm{~s}, 20 \mathrm{~s}, 25 \mathrm{~s}, 30 \mathrm{~s}, 35 \mathrm{~s}$, and $40 \mathrm{~s}$ yarn. Both single and double roving organizations were used in carded and combed yarns.

\section{MANUFACTURING PROCEDURE}

The cotton was given the usual treatment in the mill processes outlined as follows:

1. Automatic feeder.

2. Vertical opener (600 r. p. m.).

3. Breaker picker (Kirschner, 3-blade beater).

(a) 900 r. p. m., 31 blows per inch, 14 ounces lap.

4. Intermediate picker (rigid, 2-blade beater).

(a) 900 r. p. m., 39 blows per inch, 13 ounces lap.

5. Finisher picker (Rigid, 2-blade beater).

6. Card.

(a) 900 r. p. m., 40 blows per inch, 12.5 ounces lap.

(a) Cylinder, 165 r. p. m.

(b) Licker-in, 390 r. p. m.

(c) Doffer, 10 r. p. m.

(d) Weight of sliver, 55 grains.

7. Sliver lapper.

(a) Feed, 20 slivers of 55 grains each.

(b) Delivery, 1 lap of 430 grains.

8. Ribbon lapper.

(a) Feed, 4 laps of 430 grains each.

(b) Delivery, 1 lap of 400 grains.

9. Comber.

(a) Feed, 8 laps of 400 grains each.

(b) Delivery, 1 sliver of 50 grains.

(c) Waste removed, 23 per cent.

10. First drawing frame.

(a) Combed.

(1) Feed, 6 slivers of 50 grams each.

(2) Delivery, 1 sliver of 60 grains.

(b) Carded.

(1) Feed, 6 slivers of 55 grains each.

(2) Delivery, 1 sliver of 60 grains.

11. Second drawing frame.

(a) Combed and carded.

(1) Feed, 6 slivers of 60 grains each.

(2) Delivery, 1 sliver of 60 grains. 
12. Slubber ( 11 by $5 \frac{1}{2}$ ).

(a) Spindle speed, 745 r. p. m.

(b) Draft, 4.3.

(c) Feed, 1 sliver of 60 grains.

(d) Delivery, 1 roving.

(1) Count (hanks), 0.6.

(2) Twists per inch, 0.93 .

13. Intermediate ( 9 by $4 \frac{1}{2}$ ).
(a) Spindle speed (r. p. m.)
990
$\begin{array}{llll}990 & 990 & 990 & 990\end{array}$
(b) Draft (c) (2 roving, hanks)
3. 67
5. $5 \quad 3.94$
4. 4 5. 5
(d) Delivery.
0. 60
0. 60 1. 10
1. 10 1. 10
(1) Count (hanks) -
1. 10
1. 65
1. 86
2. 20
2. 75
(2) Twists per inch
1. 28
1. 56
1. 66
1. 78
1. 99

14. Fine fly frame ( 7 by $3 \frac{1}{2}$ ).

(a) Spindle speed (r. p. m.) _.... 1, $250 \quad 1,250 \quad 1,250 \quad 1,250$

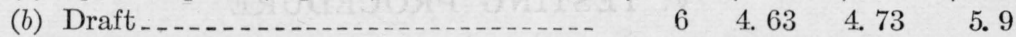

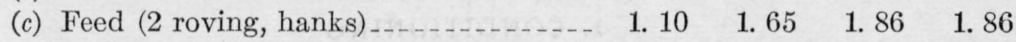

(d) Delivery
(1) Count (hanks)
3. 30
3. $85 \quad 4.40$
5. 50

(2) Twist per inch

2. 19

$\begin{array}{ll}2.34 & \text { 2. } 52\end{array}$

2. 83

15. Jack frame.

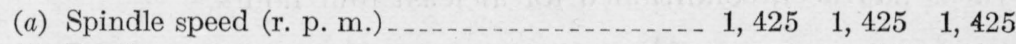

(b) Draft__.... 4 4. 7 4.5

$\begin{array}{lllll}\text { (c) Feed (2 roving, hanks) } \ldots \ldots \ldots & 3.30 & 3.30 & 3.85\end{array}$

(d) Delivery.

$\begin{array}{lllll}\text { (1) Count (hanks) } \ldots \ldots \ldots & 6.60 & \text { 7. } 70 & 8.80\end{array}$

(2) Twists per inch__._._. $3.06 \quad 3.28 \quad 3.55$

16. Spinning frame.

(a) Spindle speed_-_variable.

(b) Draft _._..._. variable.

(c) Single roving.

$\begin{array}{lllllll}\text { (1) Feed (hanks) _-_- } 1.10 & 1.65 & 2.20 & 2.75 & 3.30 & 3.85 & 4.40\end{array}$

(2) Delivery (counts) - $\begin{array}{lllllll}10 & 15 & 20 & 25 & 30 & 35 & 40\end{array}$

(d) Double roving.
(1) Feed (hanks)
2. 20
$\begin{array}{lll}3.30 & 4.40 & 5.50\end{array}$
6. 60
$\begin{array}{ll}7 . & 80 \\ 80 & 80\end{array}$

(2) Delivery (counts) -

10

15

$20 \quad 25$

30

35

40

Beginning with the slubber, the mill organizations were changed to avoid long drafts and to facilitate the work by employing as few processes as possible. The greatest number of changes occurred in the spinning processes, where the draft, twist, and spindle speeds were altered to produce the desired results.

A range of twist was obtained using twist multipliers from 2.5 to 5.0 in increments of 0.25 and from 5.0 to 8.5 in increments of 0.5 . The twists per inch for each yarn varied for each twist multiplier according to the formula

$$
T=M \times C
$$

where $T$ is the twists per inch, $M$ the twist multiplier, and $C$ the yarn count. 
The yarns were spun on ring frames, the $10 \mathrm{~s}, 15 \mathrm{~s}, 20 \mathrm{~s}, 25 \mathrm{~s}$, and 30 s yarns being spun on $13 / 4$-inch rings and the $35 \mathrm{~s}$ and 40 s yarns on $13 / 8$-inch rings. The spindles were driven from an 8 -inch drum by means of tapes which were kept tight by idler pulleys. This method kept the slippage of spindles at a minimum.

As the twist was varied, the draft was changed according to the amount of contraction, so that practically a constant yarn count was maintained. The spindle speed was also changed in order to avoid high speeds on low-twisted yarn and to follow the usual mill procedure for production.

A relative humidity of 65 per cent was maintained throughout the entire period of manufacturing.

\section{TESTING PROCEDURE}

\section{CONDITIONING}

The tests were conducted in a room having a constant temperature of $70^{\circ} \mathrm{F}$. and a relative humidity of 65 per cent, and after the yarns had been conditioned for at least four hours.

\section{SAMPLING}

Ten bobbins were taken at random from each lot of yarn. For carded yarns there were 5 different counts, each count having 17 different twists for each of the roving organizations (single and double), making a total of 170 lots. For combed yarns there were 7 counts, each count having 17 different twists for each of the roving organizations, a total of 238 lots. This made a grand total of 408 lots of yarn.

Table 1 shows the number of specimens tested.

TABLE 1.-Number of specimens tested

\begin{tabular}{|c|c|c|c|}
\hline Test & $\begin{array}{c}\text { Number } \\
\text { of } \\
\text { speci- } \\
\text { mens } \\
\text { from } \\
\text { each } \\
\text { bobbin }\end{array}$ & $\begin{array}{c}\text { Number } \\
\text { of } \\
\text { speci- } \\
\text { mens } \\
\text { from } \\
\text { each } \\
\text { lot }\end{array}$ & $\begin{array}{c}\text { Total } \\
\text { number } \\
\text { of } \\
\text { speci- } \\
\text { mens } \\
\text { (408 } \\
\text { lots) }\end{array}$ \\
\hline Breaking strength, skein. & 1 & 10 & 4,080 \\
\hline Breaking strength, single strand.... & 4 & 40 & 16,320 \\
\hline Twist & 1 & 10 & 4,080 \\
\hline Yarn count..... & 1 & 10 & 4,080 \\
\hline Diameter & 1 & 10 & 4,080 \\
\hline Angle of twist.. & 1 & 10 & 4,080 \\
\hline Total_... & 9 & 90 & 36,720 \\
\hline
\end{tabular}

3. BREAKING STRENGTH

The breaking strength of the yarn was determined both by the skein (or lea) test and by the single-strand test. The apparatus used for both tests were Scott testers of the inclination-balance type. 
The speed of the pulling drum or jaw was 12 inches per minute under no load.

In the skein (or lea) test a skein 120 yards in length was wound on a reel having a perimeter of $1 \frac{1}{2}$ yards. This skein, consisting of 80 strands, was then placed on the drums of the testing machine. These drums are 1 inch in diameter. The capacity of the machine. is 300 pounds. Careful handling minimized the overlapping of the yarn and distributed the load, which was applied more or less evenly.

In the single-strand test the yarn was clamped in small jaws of the testing machine. The distance between jaws was 6 inches. The capacity of the machine is 2.2 pounds. Care was taken to avoid disturbing the twist while the specimen was being prepared for the break. Breaks occurring at or in the jaws were disregarded.

\section{YARN COUNT}

Yarn count was determined by weighing a skein of 120 yards and then making the usual calculations according to the formula

$$
C=\frac{Y \times 453.6}{W \times 840}
$$

where $Y=$ yards in specimen, $W$ is weight in grains, 453.6 is number of grams in a pound, and 840 is the cotton constant.

\section{DIAMETER OF YARN}

The yarn was wrapped loosely around a black cardboard 1 inch wide. This was then placed on a rotary stage microscope. The sides of the yarn were brought into focus and made to coincide with the movable wire in the eyepiece. This wire was moved across the field by a screw, one turn of which moved the wire $0.5 \mathrm{~mm}$. The screw had an adjustable drumhead divided into 50 parts, one part therefore being equal to $0.01 \mathrm{~mm}$, one-tenth of which could be easily estimated $(0.001 \mathrm{~mm})$. The readings were made at the center of the scale, to insure greater accuracy.

When the wire had been made to coincide with one side of the yarn the readings on the field and drum were noted, and the wire was then moved to the other side of the yarn and the readings again recorded. The difference in each case between these two readings was the diameter of the yarn.

\section{ANGLE OF TWIST}

The angle of twist with respect to the longitudinal axis of the yarn was measured with the same apparatus used for diameter measurement, by rotating the stage so that the wire in the eyepiece was parallel to the angle of the twist in the yarn. 


\section{DISCUSSION OF RESULTS}

The test data were very voluminous, as will be noted from the number of tests made as indicated in Table 1. It was deemed advisable to correlate the results graphically rather than tabularly. Attention is therefore directed to Figures 1 to 7 . Through the points, as plotted, smooth curves have been drawn.

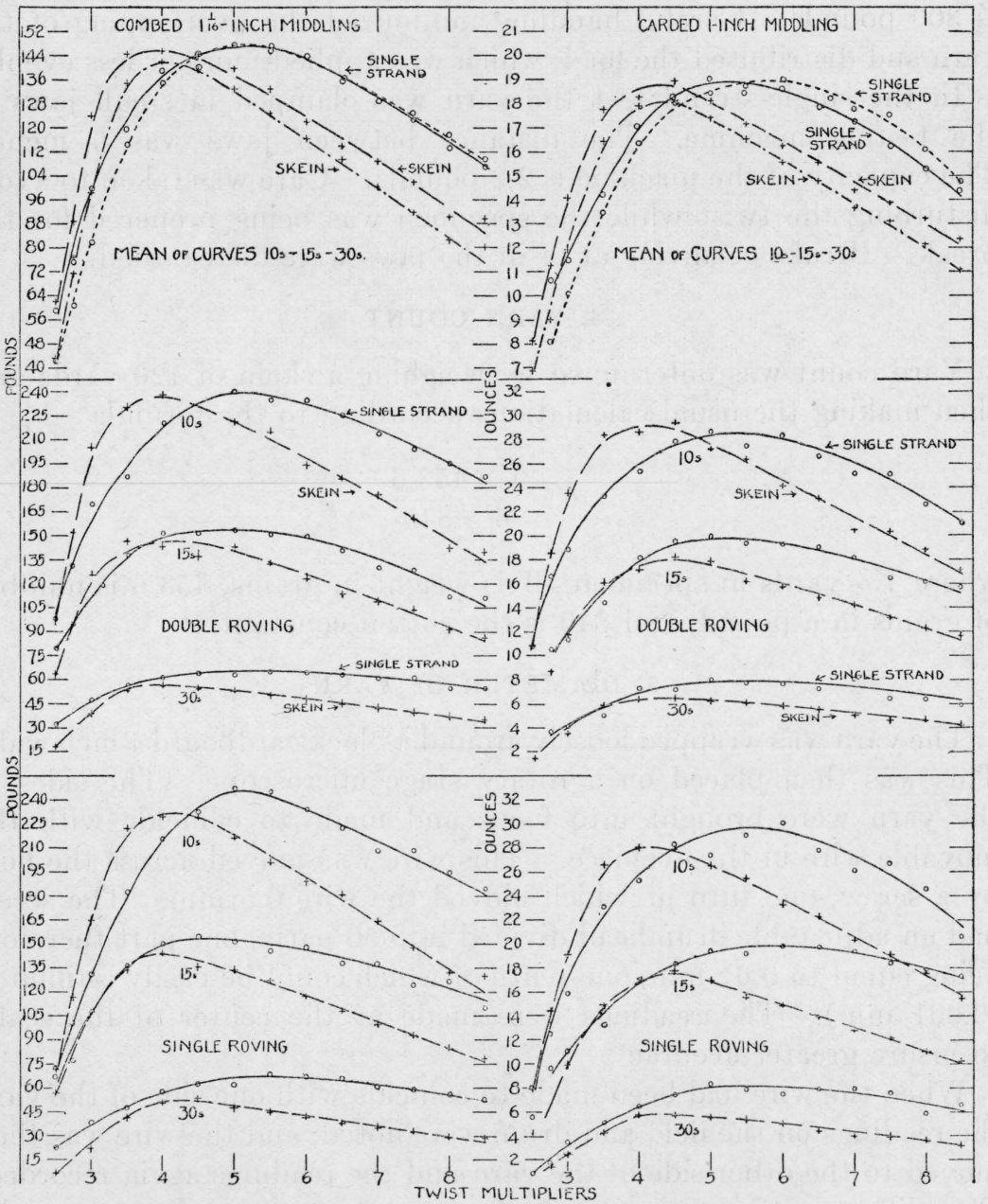

Fig. 1.-Comparison of skein and single strand breaking strength determinations as affected by twist

The scale for the skein results is given at the left; the scale for the single-strand is given in the center of the chart. The curves are plotted so that the shapes of single-strand and skein methods may be compared.

\section{BREAKING STRENGTH}

Figure 1 shows a comparison of the curves obtained by plotting the twist multiplier against the skein and the single-strand breaking strengths. The maximum strength for skein breaks was reached with a twist multiplier of about 4.25 , whereas for the single-strand 
method the maximum breaking strength was reached with a twist multiplier of about 5.25. This may be partially explained by considering that the single-strand result represents an average of a number of tests (in this case 40), including high, low, and medium breaks, whereas the skein test, although presumably the average of a large number of single-strand tests, is really an average of the medium

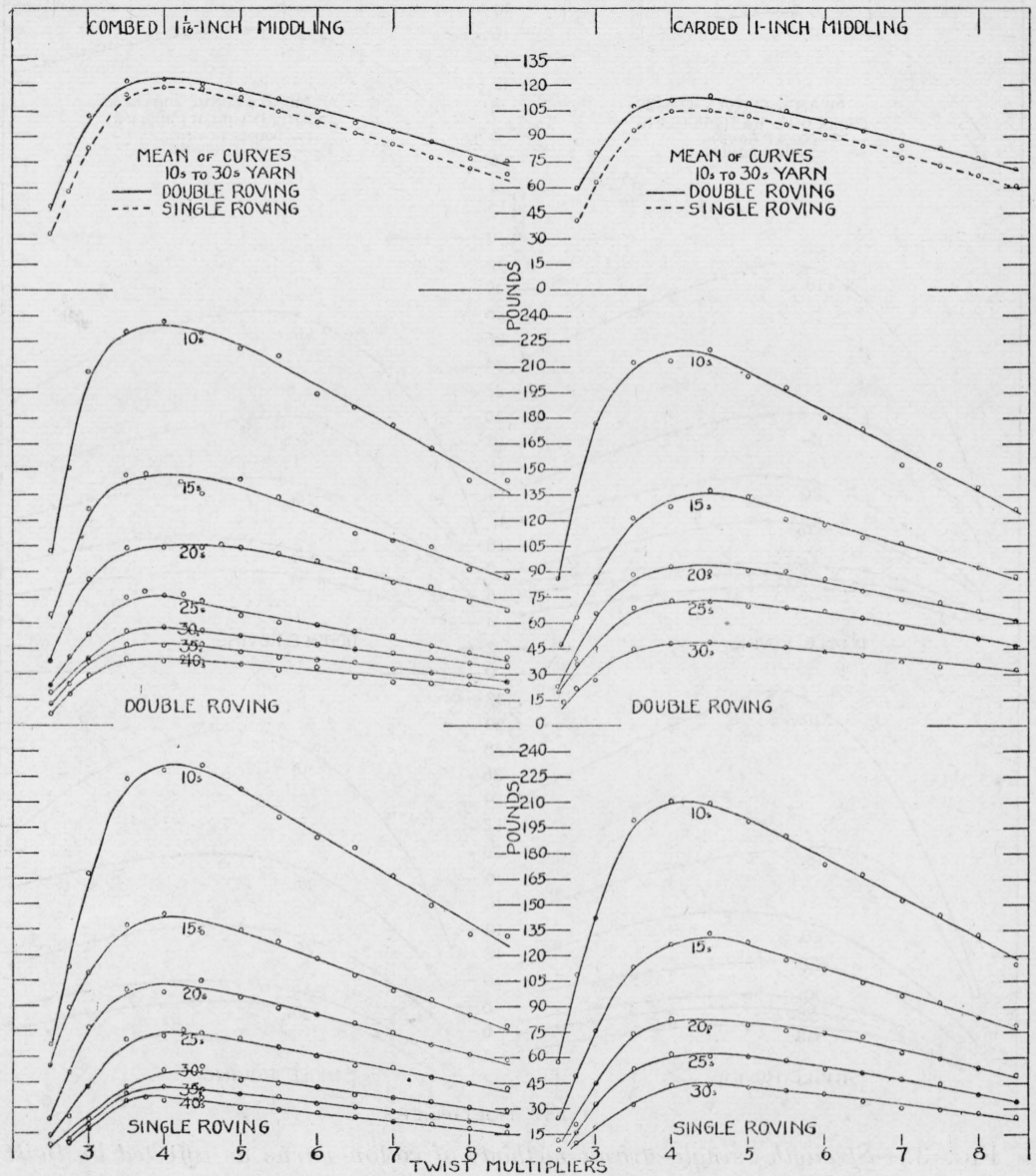

Fig. 2.-Strength (skein method) of cotton yarns as affected by twist

Yarns with different twist factors were spun from single and double roving; made of combed $1 \frac{1}{16}$ inch and carded 1-inch staples, middling grade cotton. Results are given for the various counts, and a mean of the results is given at the top to show the average gain obtained by using the double roving.

and low breaks. The factors of friction, distribution of tension, and variation in the stretch of the individual yarns appreciably influence the results. At best, the skein tests grade the samples in the same quantitative order as a single-strand test. ${ }^{1}$

The strength tests by the skein method, which are plotted in Figure 2 , indicate the benefit obtained by using a double-roving instead of a

1 Confer Hall, J. Text. Inst., 15, T223; 1925.

$110818^{\circ}-28-2$ 
single-roving organization. Using low-twist multipliers, the advantage gained is as high as 15 pounds in some instances. The singlestrand tests (fig. 3), however, although in general agreement with the above statement in regard to the low-twist multipliers, indicate that little if any advantage is gained for high-twist yarns.

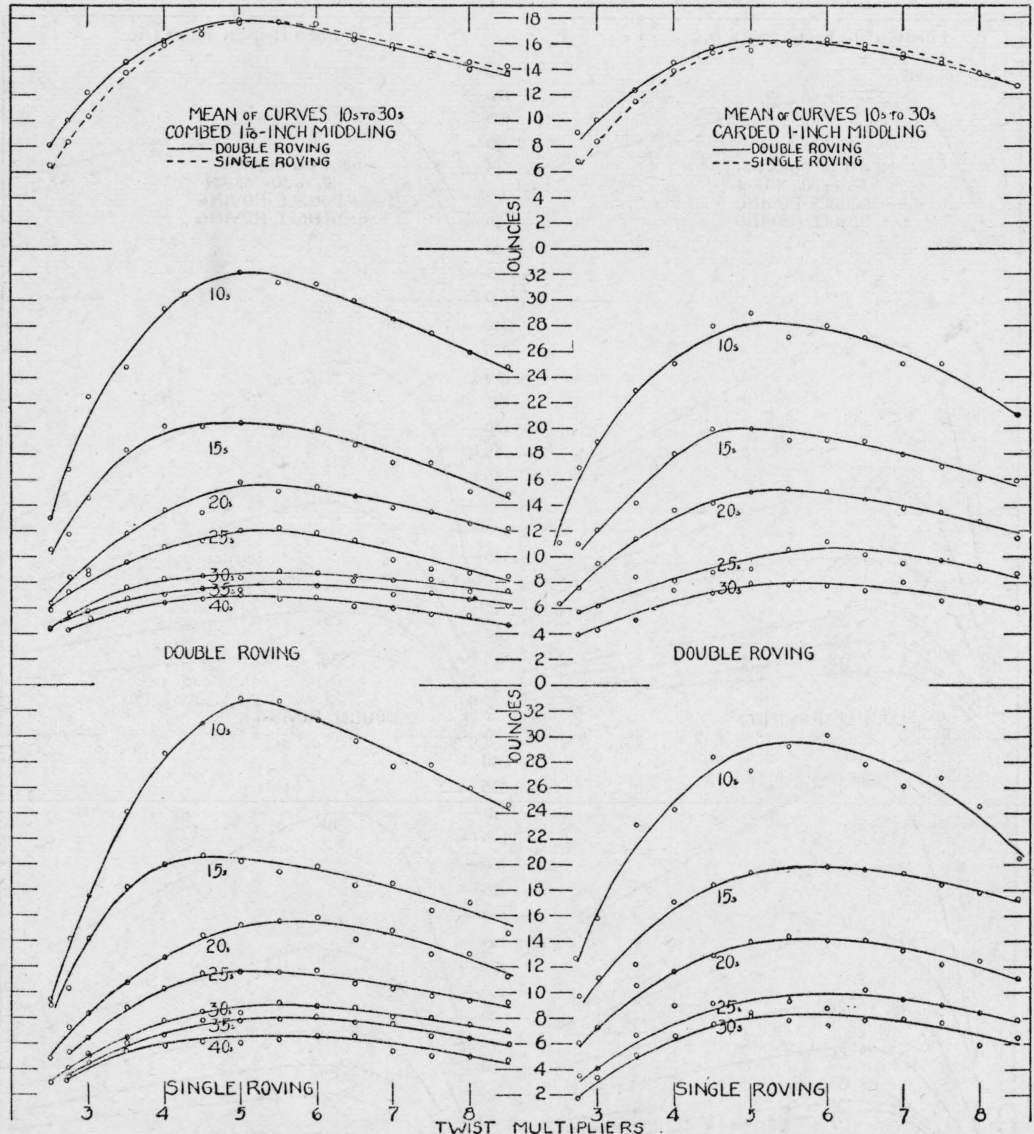

Fig. 3.-Strength (single-strand method) of cotton yarns as affected by twist

Yarns with different twist factors were spun from single and double roving; made of combed $1 \frac{1}{16}$-inch and carded 1-inch staples, middling grade cotton. Results are given for the various counts, and a mean of the results is given at the top to show the average gain obtained by using the double roving.

The advantage of using the combing process is indicated to some extent in Figure 4, although it is impossible to state how much of the increased strength is due to the greater staple length and how much is due to the combing process.

There is one outstanding fact shown by Figures 1 to 4 : The strength of a yarn increases with twist up to a certain point, then decreases as 
further twist is added. In a previous bureau paper ${ }^{2}$ the following statement occurs:

The twist is an important factor in obtaining the strength of a yarn. In the twisting process the fibers are entwined around and cling to each other so that

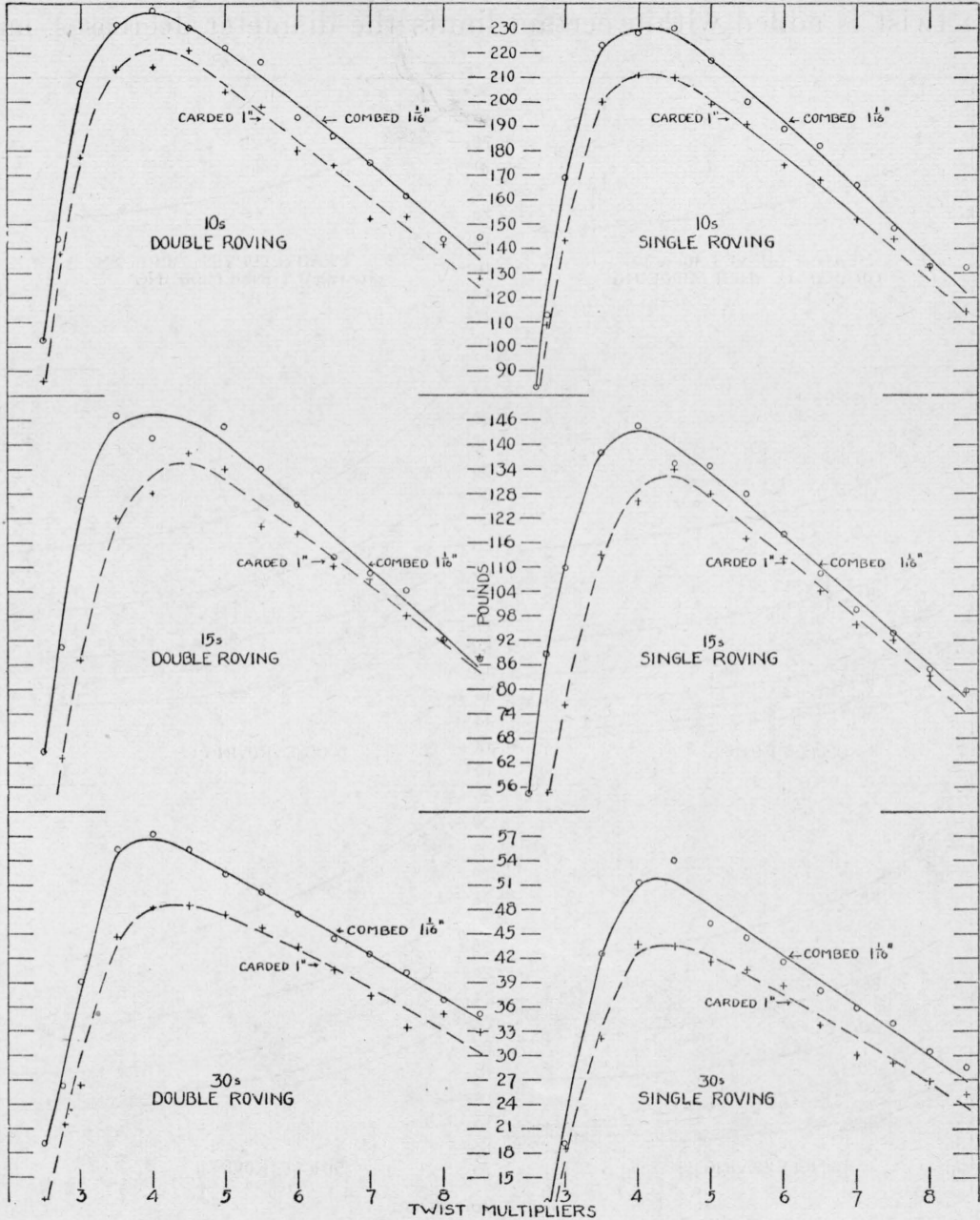

FIG. 4.-Strength (skein method) of combed and carded cotton yarns as affected by twist

Yarns were spun from single and double roving. It is to be noted that 1-inch cotton was used for the carded and $1 \frac{1}{4}$-inch for the combed yarn; therefore the curves are not strictly comparable.

they resist efforts to slip by each other. Theoretically the maximum strength is obtained when sufficient twist is given which will, with minimum strain to the individual fibers, prevent any slipping when force is applied in a longitudinal

\& MeGowan, Schoffstall, and Mercier, Efiect of Twist on Pima Yarn, B. S. Tech. Paper No. 278, p. 89; Feb. 11, 1925. 
direction. Beyond this point the strength decreases, and this decrease can be continued until the yarn breaks under no longitudinal strain, but mereiy from the shearing action of the twisting.

\section{DIAMETER AND ANGLE OF TWIST}

The covering power of a yarn is directly affected by the diameter. As twist is added within certain limits the diameter decreases, as is

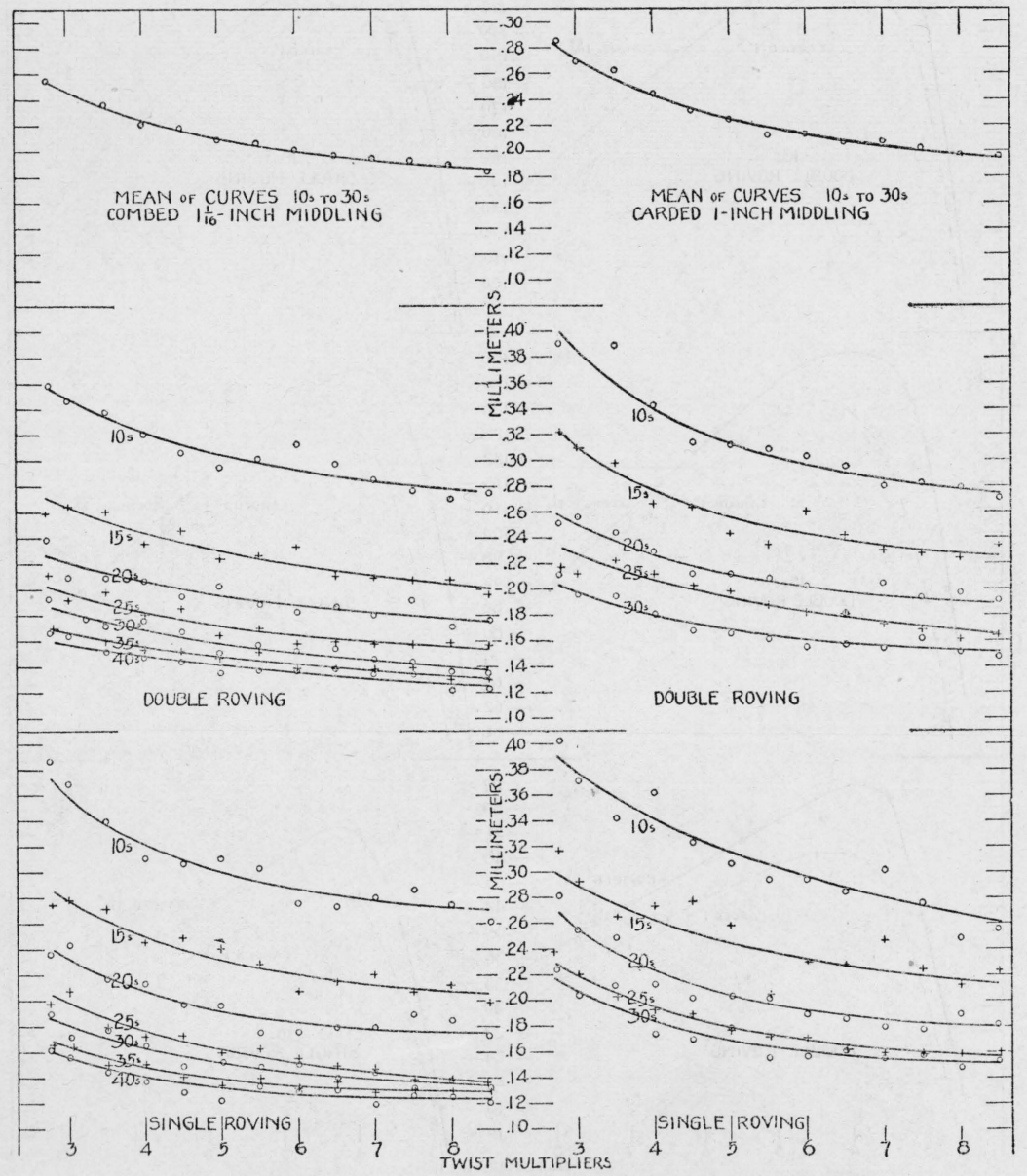

FIG. 5.-Diameters of cotton yarn as affected by twist

Groupings of the yarn spun from single and double roving for the carded and combed lots are given; also the mean of the curves.

shown by Figure 5. This feature is important. For example, the yarn for underwear cloth must be soft and make up into cloth in such a way that the interstices between the stitches are a minimum. On the other hand, a voile is made from yarns which form comparatively wide interstices as compared with the surface covered by the yarn itself. 
The relation of the angle of twist to the yarn properties is seldom fully realized. There is little doubt that the angle of twist affects light reflection from the surface of the yarn or cloth made from the yarn. While the data in the present study were being collated a paper by Tenney ${ }^{3}$ indicated that this feature of yarn testing was receiving attention in other more practical fields. Tenney has the following to say, which is of interest in this connection:

The theory of parallel lines in the design of cloths is of great interest. The fiber angle, angle of twist, and the angle of the axis of the yarn are all very important. The angle of twist offers not only an exact means of determining the average twist in single yarns $* * *$ but it is a measure of the hardness or softness of the yarn and fabric of which it is a part.

In the design of cotton warp sateens the nearer the parallel fibers of the yarn conform to the angle of the twill the smoother will be the face of the cloth. The difference between a smooth-face and a twill-face sateen is determined by the apposition or coincidence of the twill angle and the fiber angle.

Another interesting example given by Tenney of the application of definite knowledge of angle of twist was in the construction of cotton broadcloths, in which increased luster was obtained by employing yarns with a definite angle of twist which made the ply yarns seem to split into pairs at the points of intersection, giving twice the number of parallel lines per inch.

Luster of silk materials is enhanced or subdued by manipulation of the twist in the yarn.

The quantitative data on angle of twist obtained in this study are graphically represented in Figure 6.

\section{CONTRACTION}

In order to maintain a constant count in each yarn while increasing the twist, the contraction in length due to increase in twist was corrected by changing the draft. These draft-change curves are shown in Figure 7.

When increasing from a twist multiplier of 3 to one of 4.75 (using: the same roving), the draft had to be increased from 9.25 to 9.75 . Other draft increases are in proportion, the curves being of the same general character.

\section{THE USE OF THESE DATA IN THE MILL}

Questions may arise as to the application of the data here presented in the everyday operation of a cotton mill. Variations from the actual results obtained here may, of course, be expected, even when the same staple of cotton and the same mill organizations are used. Such features as relative humidity in the mill, slippage of spindles,

\footnotetext{
3 Tenney, A. M., “Microscopic research in industry,” Textile World, p. 2033, Mar. 26, 1927 (a paper read before Committee D-13, Am. Soc. Test. Mat. at Mass. Inst. Tech.; March, 1927).
} 
and variations in test procedure will change the result somewhat. However, it is to be noted that for the most part the data given follow smooth curves very closely, and it should be possible in cases where results are affected by some constant (such as spindle slippage) to interpolate the actual figures from these charts.

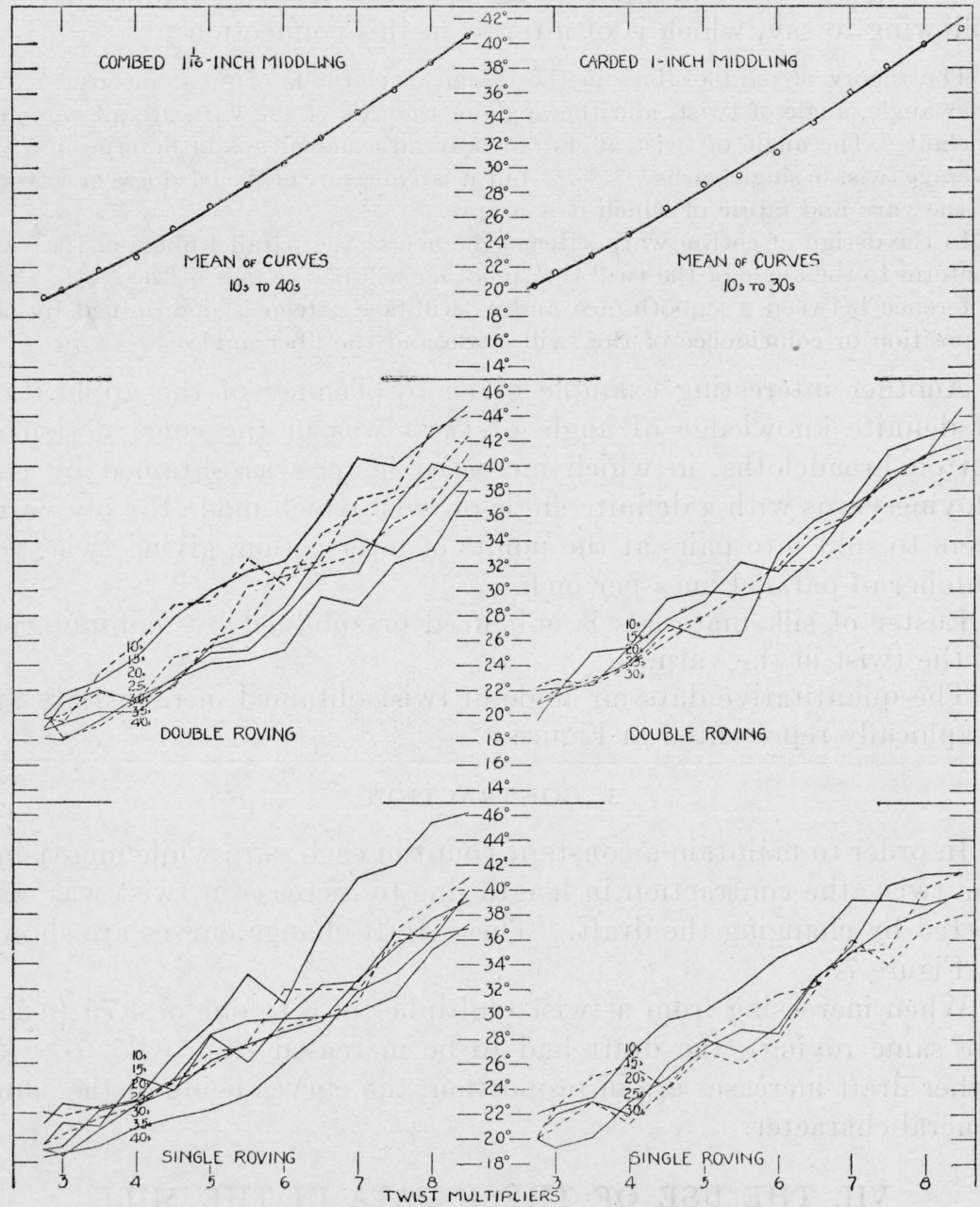

Fig. 6.-Angle of twist of cotton yarn as affected by twist

Groupings of the yarn spun from single and double roving for the carded and combed lots are given; also the mean of the curves. Several of the lines connecting the points are broken lines to aid in following the points.

Figure 1 shows markedly the effect of the test method on the result and should enable a mill to some extent to correlate data obtained by either of the two commonly used methods of determining breaking strength. The curves obtained by the two methods separately are shown in Figures 2 and 3. It is believed that the single-strand 
method presents a better measure of the breaking-strength relation of the yarn, because the results are an average of a number of breaks, each made separately and including high, low, and medium values.

It was observed that yarn of the twist multiplier which would give maximum strength as indicated by the skein method had less tendency

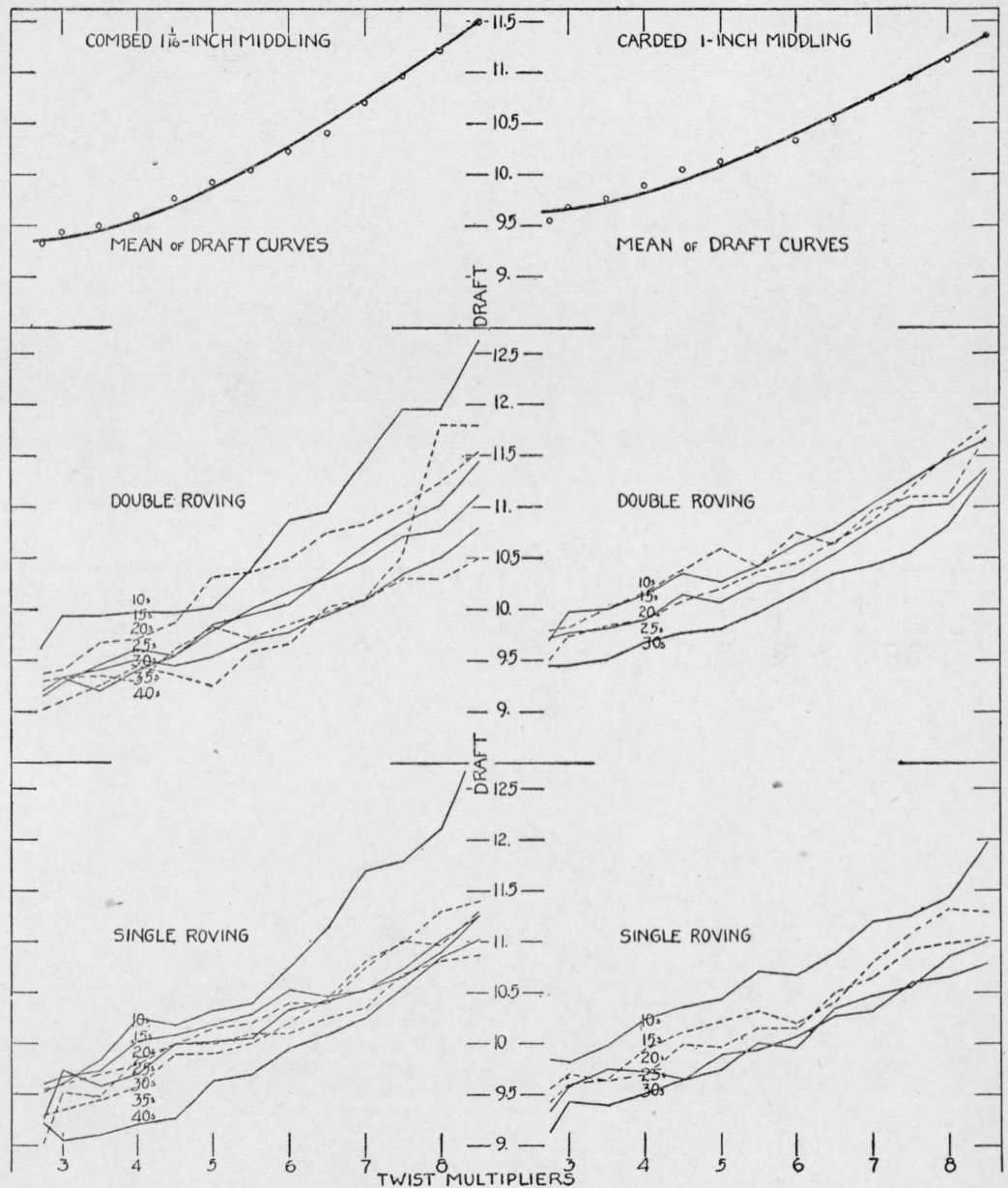

Fig. 7.-Draft as affected by twist

The amount of draft necessary to maintain constant counts is plotted against the twist multiplier. Groupings of the yarn spun from single and double roving for the carded and combed lots are given; also the mean of the curves. Several of the lines connecting the points are broken lines to aid in following the points.

to kink. This made it very much easier to handle, and this is, of course, an important factor in the choice of twist multiplier.

Figures 1, 2, and 3 also show that equal breaking strengths can be obtained at two points on the curve, one with a low-twist multiplier, the other with a high. The choice of the proper twist mul- 

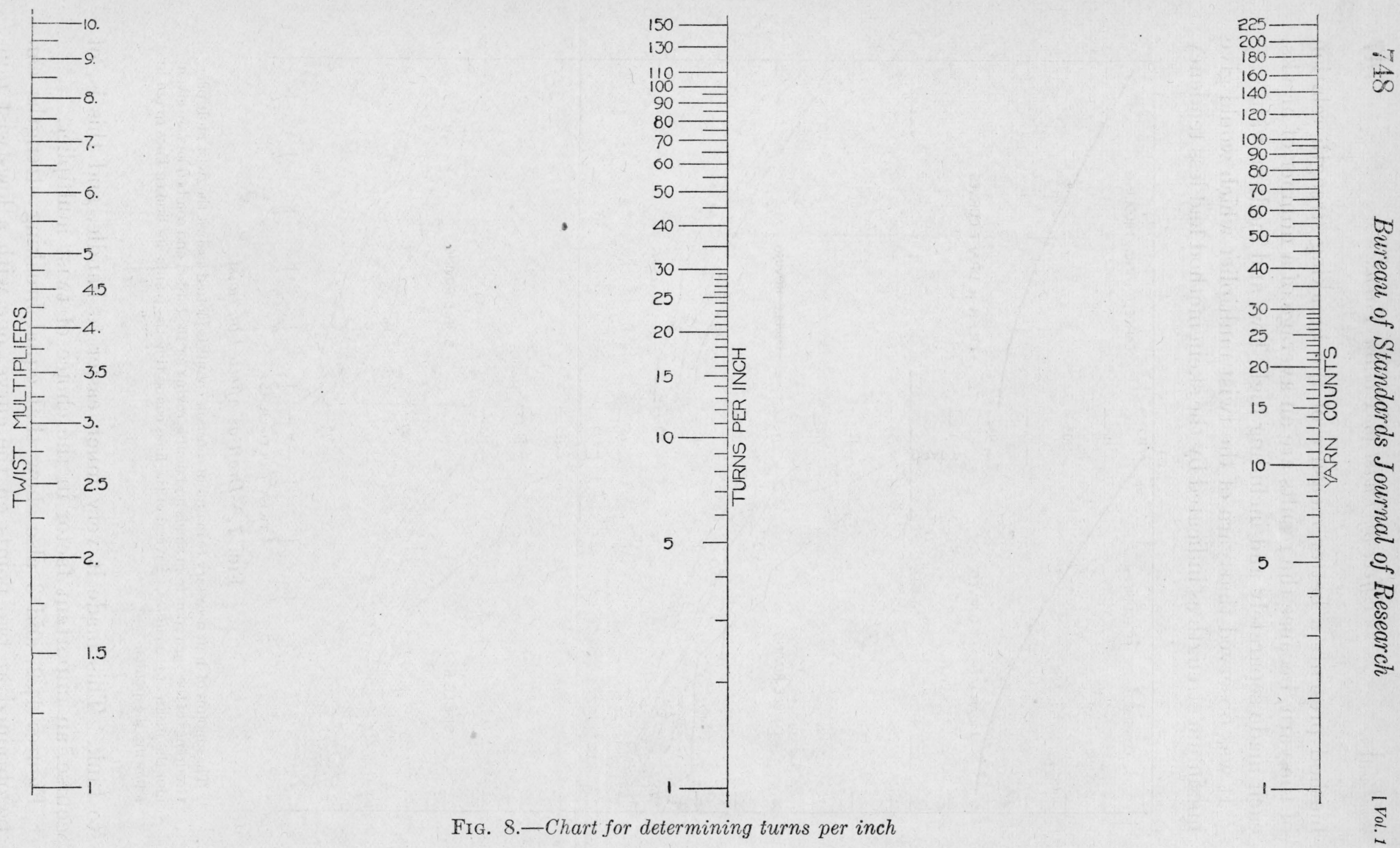

FIG. 8.-Chart for determining turns per inch

To determine turns per inch in a yarn, place straightedge on the count of yarn and on the twist multiplier to be used. The turns per inch are read on the center scale. 

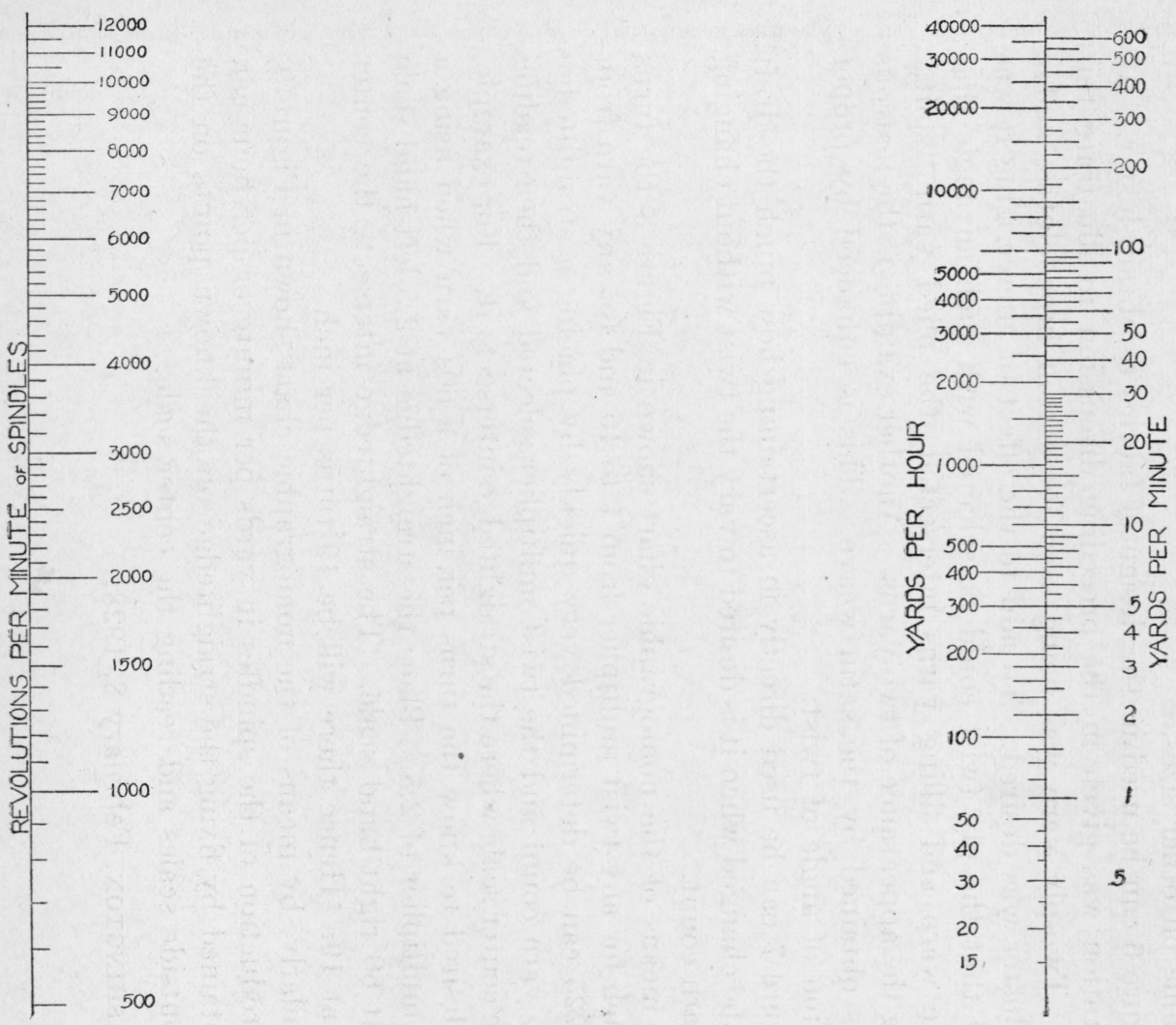
tiplier will depend on what other qualities are desired in addition to strength. If strength only is required, the lowest-twist multiplier which gives the desired strength should be selected because of the lower production costs. If soft yarns are desired, select the lowertwist multiplier. Crêpes and voiles would require yarns with hightwist multiplier.

Figure 4 is useful in determining how much advantage in strength is gained by the use of the combing process.

Figure 5 will be useful when designing a fabric for covering power. Covering power of a yarn is determined by its diameter. It will be noted, for example, that the decrease in diameter resulting from a change from a twist multiplier of 3 to 4 for a 10 s combed yarn is $0.04 \mathrm{~mm}$, or almost 10 per cent. The percentage change is about the same on other sizes.

Figure 6 can be used in the design of fabrics to obtain luster. An illustration was given in the preceding discussion to illustrate this case. Two-ply yarn was being used for cotton broadcloths, and a high luster was desired. To add to the effect of mercerizing it was found that the ply twist could be selected with such an angle that as the warp and filling yarns intersected, the plied yarn "split," giving the appearance of two yarns. Another example is the lustrous effects obtained by the satin weave. This is enhanced by proper selection of angle of twist.

Figure 7 can be used directly in ascertaining how much the draft must be changed when it is desired to vary the twist without changing the yarn count.

By means of the nomographic chart shown in Figure 8 the turns per inch for any twist multiplier from 1 to 10 and for any yarn from 1 to 225 can be determined very quickly by placing a straightedge at the yarn count and the twist multiplier selected and then reading on the center scale where the straightedge intersects it. For example, it is desired to know the turns per inch of a 60 s yarn when using a twist multiplier of 2.5. Place the straightedge at 2.5 left-hand scale and at 60 right-hand scale. The straightedge intersects the center scale at 19 . Hence there will be 19 turns per inch.

Similarly, by means of the nomographic chart shown in Figure 9, the production of the spindles in yards per minute or per hour can be obtained by fixing the straightedge on the known points on the two outside scales and reading the center scale.

Washington, February 8, 1928. 